http://dx.doi.org/10.18232/alhe.1146

Artículos

\title{
Propietarias en la ciudad de México durante la coyuntura de la reforma liberal
}

\section{Women owners in Mexico City during the conjuncture of liberal reform}

\author{
Irina Córdoba ${ }^{1,}$ * (DD 0000-0002-3411-647X \\ ${ }^{1}$ Universidad Autónoma de Baja California, Mexicali, Baja California, México. \\ *Correspondencia: irina.cordoba@uabc.edu.mx
}

Resumen. Los cambios económicos que promovió la Ley de Desamortización de Fincas Rústicas y Urbanas de Corporaciones Civiles y Eclesiásticas, redactada en junio de 1856 por el ministro de Hacienda, Miguel Lerdo de Tejada, transformaron el acceso de las mujeres a la propiedad. Por medio de una investigación documental en el Fondo Antiguo del Archivo Histórico de Notarías de la Ciudad de México y el análisis del cambio legal con perspectiva de género, se contextualizan los argumentos de 29 mujeres que lograron paulatinamente la propiedad de los bienes adjudicados en el otoño de 1856. La interpretación subraya la importancia de la esfera económica para entender el cambio social, sin abatir completamente los límites al ejercicio de este derecho.

Palabras clave: corporaciones; desamortización; mujeres; propiedad; derechos.

Abstract. The economic changes promoted by the Law on the Confiscation of Civic and Ecclesiastical Rural and Urban Farms, written in June 1856 by the Minister of the Treasury, Miguel Lerdo de Tejada, transformed women's access to property, however, it did not completely brake the limits to the exercise of this right. This article contextualizes the arguments of 29 women who gradually achieved ownership of the

CÓMO CITAR: Córdoba, D. I. (2021). Propietarias en la ciudad de México durante la coyuntura de la reforma liberal. América Latina en la Historia Económica, 28(2), 1-24. DOI: 10.18232/alhe.1146 
assets awarded in the autumn of 1856 through a documentary research in the Ancient Collections of the Historical Archive of Notaries of Mexico City, and the analysis of legal change with a gender perspective. The interpretation underlines the importance of the economic sphere to understand social change.

Key words: corporations; confiscation; property; women; rights.

JEL: N36; N46; N96.

Recibido: 15 de noviembre de 2019

Aceptado: 20 de enero de 2020

Publicado: 22 de enero de 2021.

\section{INTRODUCGIÓN}

El proceso de desamortización ha sido estudiado de manera amplia. Los reveses que atravesó, entre los que se cuentan la abrogación de la Ley Lerdo en enero de 1858, cuando estalló la guerra de Tres Años y la posterior confusión del proceso al promulgarse la Ley de Nacionalización de Bienes Eclesiásticos en 1859, han sido analizados por diversos autores. Desde la obra pionera de Jan Bazant (1977) y los cuestionamientos políticos de Robert J. Knowlton (1985), se ha construido una vasta historiografía encargada de estudiar los motivos y consecuencias del proceso desamortizador, tanto en su vertiente eclesiástica como en la civil, donde se enfatizan sus distintos ritmos, temporalidades y efectividad. Dos balances se encuentran en Mijangos (2018b, pp. 58, 90, 110, $156,164-166,171-172,174-175,177-179,184-193,199-200,227,237,240)$ y Marino (2001, pp. 33-44).

La propuesta de este artículo visibiliza la participación de las mujeres en el proceso de individualización de la propiedad. Además de reflexionar sobre la capacidad jurídica de la mujer para ser propietaria, la investigación se ha respaldado en trabajos que muestran la debilidad institucional de los preceptos liberales y la ausencia de linealidad en la participación de los sujetos; ambos puntos son el anclaje para comprender la complejidad que atravesó el siglo. Las investigaciones con un enfoque regional han sido invaluables para valorar el peso de las mujeres en el proceso liberal. Se distinguen los textos de Morales (1995) y su enfoque prosopográfico, así como los de Sánchez (2007), Bazant (1979) y González (2011), que subrayan la necesidad de observar y comparar la experiencia de la ciudad de México frente a espacios acotados, no siempre en sintonía con los sucesos de la capital del país.

Otra perspectiva útil para la propuesta es la de Anne Staples (2009) sobre los temores que generaron los proyectos de secularización. En contraparte, la aportación de Francisco Javier Cervantes (2004) proporciona un punto de partida para la comprensión de las respuestas sociales asertivas frente a la ley.

Este artículo está dividido en cuatro apartados. En el primero se referirán las características generales de la participación de las mujeres en el proceso de desamortización en la ciudad de México; en el segundo se tratará lo relativo al acceso de las mujeres al ejercicio de la propiedad; en el tercero se hablará de la importancia del derecho de traslación para el erario público y, finalmente, en el cuarto apartado se referirán las estrategias que siguieron quienes lograron hacerse con la propiedad de los bienes adjudicados. 


\section{LAS MUJERES Y LA DESAMORTIZACión EN LA GiUdAD DE MÉXICO}

Una de las caracterizaciones más extendidas sobre las mujeres durante el siglo xIX deriva de la conclusión a la que estudiosas como Carmen Ramos (2006) y Silvia Arrom (1988) han llegado en sus obras: la centuria ofrece un discurrir marcado por el creciente conservadurismo que, en el caso de la mujer, coloca en puntos extremos a un periodo virreinal desregulado y a un porfiriato más tradicional.

Gran parte de la producción pictórica del siglo (Velázquez, 2018) asiente con ese modelo que representó a las mujeres del periodo como un crisol en el que se entrelazaron la ingenuidad, la religiosidad y la ignorancia. El diálogo ficticio ofrecido por Guillermo Prieto en Memorias de mis tiempos muestra de manera ejemplar lo anterior:

-Mamá, ¿̇he cometido yo esto del abigeato?

-Según, hijo: si has estado fuera de la iglesia, no. Porque la mamá estaba en la inteligencia de que el abigeato (que es el robo de bestias) era una cosa como sacrilegio (Prieto, 1992, p. 241).

Aunque esta imagen no se puede soslayar, resulta sugerente contrastarla con las palabras del ministro francés, Alexis de Gabriac, quien, en febrero de 1856, mediante su correspondencia diplomática, advirtió: "existe en México una influencia, latente pero certera, que juega un papel en la política interior del país: la influencia de la mujer" (Díaz, 1963, p. 250). La percepción de Gabriac visibiliza a un grupo social que vio en los cambios, que denominamos Reforma, una oportunidad para afirmarse en el espacio público, sin que esa afirmación haya estado siempre en armonía con los cambios propuestos por la legislación liberal.

Esa influencia fue contemplada con agudeza por el francés y con evidente desprecio por algunos de los liberales más emblemáticos del periodo. Francisco Zarco, como cronista del Congreso Constituyente, se cuestionaba perplejo: “¿qué importan a las mujeres las cuestiones de la libertad religiosa? Viviendo en el hogar doméstico, siendo el ornato de sus familias, formando el corazón de sus hijos, ¿̇qué tienen que ver con las cuestiones que agitan a la sociedad?” (Zarco, 1957, p. 336). Las representaciones femeninas contra la libertad de cultos, que tuvieron lugar en 1856, desquiciaban al liberal que consideraba que el cuidado del hogar era la actitud más patriótica que podrían realizar las mujeres. En el mismo sentido se pronunciaba el editor Mariano Galván, quien resulta de enorme relevancia para este estudio, pues comentó una de las herramientas jurídicas que establecieron la relación de las mujeres con el derecho de propiedad: el Nuevo Febrero Mexicano. Para Galván "siendo el matrimonio una sociedad... [era] indispensable que haya en ella una cabeza o autoridad que la dirija y mande”. Este papel correspondía al varón, "por sus facultades físicas e intelectuales [porque] tiene más luces y más experiencia que la mujer” (Galván, 1851, t. I, p. 40).

Algunos trabajos de corte biográfico y prosopográfico han reflexionado sobre mujeres de la elite que operaron como agentes económicos. Destacan los casos documentados por Anne Staples (2004) y Alma Parra (2018), quienes han historiado a mujeres que quebrantaron los mecanismos que, institucionalizados o no, pretendieron reducirlas al ejercicio de lo que los autores del periodo llamaron domesticidad patriótica. Mujeres que rompieron y jugaron con los modelos de conducta del periodo han sido visibilizadas por diversas investigaciones históricas (Mijangos, 2018b). De este modo, el objetivo de estas páginas es sopesar la experiencia concreta de algunas adjudicatarias en el marco de la llamada Reforma liberal, lo que tiende a revertir la marginalidad historiográfica de la mujer en el proceso y en el siglo. 
En su Memoria de Hacienda..., Miguel Lerdo de Tejada señaló que en el Distrito y departamento de México se adjudicaron y remataron fincas por un total de 13029115.52 pesos. De esa cantidad, 8905134.40 pesos se originaron en adjudicaciones y 4123981.12 pesos derivaron de remates. En ingresos totales, él mismo advirtió que se obtuvieron 1083611.01 pesos, de los que 675308.73 ingresaron a las arcas en efectivo, 196273.02 en bonos de la deuda interior consolidada y 112029.26 en certificados de la tesorería general (Lerdo de Tejada, 1857, pp. 11-12, 150-289).

En total, 1211 adjudicaciones se celebraron para arrojar el monto señalado. De ellas, según el Fondo Antiguo del Archivo General de Notarías de la Ciudad de México (AGncm), 333 (27.49\%) fueron efectuadas por mujeres. Estrictamente hablando, sólo 302 adjudicaciones se realizaron en la ciudad, 18 correspondieron a bienes localizados en las municipalidades de Tacubaya y Azcapotzalco y trece a bienes de comunidades fuera de la traza urbana; sin embargo, las adjudicatarias residían en la ciudad de México y ante sus notarios y jueces protocolizaron las adjudicaciones.

Para realizar estas 333 adjudicaciones, 353 mujeres concurrieron por sí, apoderando a un tercero e incluso representando el interés de alguien más, a 34 de las 42 notarías activas ese año. En 261 casos sólo concurrió una mujer a realizar la adjudicación, pero hubo 72 adjudicaciones en las que participaron dos o más mujeres. Por medio de las 333 escrituras de adjudicación se hizo el avalúo de 355 bienes y se realizaron 327 pagos por derechos de traslación o alcabala, un gravamen a la transmisión de la propiedad. De igual modo, 29 de las 353 adjudicatarias se hicieron con más de una propiedad en virtud de la Ley Lerdo, ya sea en una o en varias operaciones.

Las discordancias entre las cifras anteriores dan idea de las dificultades con las que el proceso de desamortización se desarrolló y de las deficiencias de las fuentes con las que hoy cuenta el historiador. El primer desfase, entre los pagos de alcabala (327) y las adjudicaciones (333), obedece a que dos pagos de derechos comprendieron ocho escrituras $(325+8=333)$.

El segundo, entre el número de adjudicaciones (333) y el número total de bienes sometidos a avalúo (355), se debe a que en 329 escrituras se hizo un solo avalúo sobre la propiedad corporativa adjudicada. En cuatro adjudicaciones los bienes en cuestión fueron subdivididos con los avalúos correspondientes dando un total de 26 terrenos o bienes adjudicables, sólo se cobró una alcabala que las nuevas propietarias abonaron con base en la extensión de tierra adjudicada $(329+26=355)$.

El tercer desfase, entre el número de alcabalas pagadas (327) y los bienes objeto de avalúo (355), es resultado de que 321 alcabalas sólo se refirieron a un bien y seis agruparon 34 bienes $(321+34=355)$.

Del universo de 333 mujeres, únicamente 29 alcanzaron la propiedad de los bienes, pues satisficieron la deuda que contrajeron al adjudicarlos. Esto se relaciona con una intención, pero también con la capacidad jurídica que se le reconoció a aquellas para acceder a la propiedad; la interseccionalidad obliga a mirar la condición de clase y el estado civil como elementos de peso para explicar la manera como el modelo femenino imperante comenzó a modificarse en algunos casos y en algunas familias (Viveros, 2016). Los argumentos expuestos por estas mujeres y el contexto de cambio legal en el que actuaron son el objetivo de este artículo. 


\section{EL ACCESO DE LAS MUJERES AL DERECHO DE PROPIEDAD}

Históricamente, la capacidad contractual de las mujeres ha encontrado límites para ejercer el derecho de propiedad. Al margen de las restricciones que la clase social, entendida como una mayor o menor capacidad económica, impone en todo momento y a cualquier individuo para acceder a la propiedad, la sociedad novohispana y la del llamado periodo de transición jurídica sujetaron la capacidad de las mujeres para ser propietarias a dos aspectos: el estado civil y la edad.

Entre 1821 y 1870 se vivió un periodo de transición jurídica en el país, es decir, la coexistencia de viejas normas españolas con las disposiciones que los congresos del nuevo Estado emitían. Las obras de doctrina jurídica, nacidas en un contexto español, fueron reimpresas y adicionadas por juristas mexicanos; el Nuevo Febrero Mexicano, útil para esta investigación por presentar las reglas vigentes en la época, se adscribe a este tipo de obras (Caballero, 2005, p. 271; González, 1998, pp. 155-156).

Ya en la época novohispana, la mujer contó con personalidad jurídica, lo que significó que sus acciones u omisiones constituyeron el contenido de normas y que tenía ciertas capacidades para actuar, esto es, para producir efectos jurídicos por su voluntad (González, 1998, p. 43). Sin embargo, la capacidad de la mujer para litigar en tribunales estuvo restringida. Las mujeres podían actuar en ciertas causas civiles y criminales, pero se creyó que hacerlo era poco "decoroso". Algunos juristas, dando forma a cierta idea de género -y aunque la realidad contraviniera esa idea-, sugirieron que era preferible la mediación de un procurador que actuara en representación de las mujeres ante jueces y escribanos, y de ese modo no se pusiera en duda su honestidad (Curia filípica, 1991, pp. 177, 372). Incluso, en enero de 1857, el primer intento de Ley del Registro Civil señaló que sólo "en casos de absoluta necesidad" las mujeres podrían ser testigos en los actos del registro (Dublán y Lozano, 2004, t. vIII, núm. 4875, p. 367).

Los ordenamientos jurídicos indican que sólo las mujeres viudas y las célibes pudieron actuar o administrar sus bienes sin obstáculos (Arrom, 1988, p. 72). Las mujeres solteras podían celebrar contratos sin tutela una vez cumplidos los 25 años -21, a partir de 1863 en el Distrito Federal y Territorios-, es decir, cuando adquirían la categoría sui juris o libres de toda patria potestad. Si el tutor las consideraba capaces, podían administrar sus bienes desde los 18 años (Dublán y Lozano, 2004, t. Ix, núm. 5799, p. 575; Galván, 1851, t. I, pp. 105, 137; González, 1998, pp. 46-47). Asimismo, "si un hombre moría intestado y sin herederos, su viuda heredaba todo el patrimonio" (Arrom, 1988, pp. 75-76, 81). Por su parte, viudas y solteras mayores de edad pudieron

comprar, vender, permutar, ceder, transigir, donar, tomar y dar prestado, comparecer en juicio, y hacer otros contratos, como igualmente obligarse por su acreedor o consentir en ser reconvenida por lo que éste debe; pero aunque se la puede compeler judicialmente [...] procediéndose en caso necesario contra sus bienes, no ha de obrarse nunca contra su persona, ni se la ha de poner presa [...] bajo el supuesto que no puede la mujer renunciar este privilegio (Escriche, 1993, p. 457).

Las mujeres casadas vieron acotada su capacidad para actuar en la materia. Estas entraron en contacto con tres tipos de bienes: gananciales, dotales y parafernales.

Los bienes gananciales o de la comunidad fueron administrados por el cónyuge. Los llamados dotales constituían una aportación femenina para la satisfacción de las necesidades derivadas del matrimonio; su administración quedó también en manos del cónyuge, quien también gozó 
del usufructo de los mismos. Los bienes parafernales fueron bienes adquiridos antes del matrimonio o en su transcurso por alguna sucesión o título lucrativo. Estos bienes, también llamados extradotales, podían ser administrados por el marido de la mujer casada si esta así lo disponía. En la edición del Febrero Mexicano, hecha en 1834, se anotó que el marido tenía el dominio y usufructo de estos bienes si al momento del matrimonio no se pactaba otra cosa. Un cambio sutil se introdujo en el Nuevo Febrero de 1851, donde se indicó que el marido podría administrarlos sólo si expresamente lo disponía su cónyuge, pero no percibiría el usufructo de los mismos (Curia filípica, 1991, p. 301; Escriche, 1993, p. 79; Galván, 1851, t. I, p. 81; Rodríguez de San Miguel, 1991, t. II, p. 473).

Además de este cambio, sutil, la ley facultó a la mujer casada para administrar su patrimonio e, incluso, para actuar ante tribunales. Por ejemplo, podía reclamar ante jueces el despilfarro en la administración de la dote. Sin embargo, bajo un argumento de defensa que entrelazó las nociones de protección, restricción y privilegio, la mujer fue definida como un ser frágil y pundonoroso. Esta percepción limitó su capacidad para administrar su patrimonio pues, se explicaba, su temperamento carecía de fortaleza; también existieron restricciones para que se desempeñara como fiadora (Arrom en Deere y León, 2002, p. 46; Escriche, 1993, p. 456).

La figura del permisionario, el marido que autorizaba a la cónyuge para celebrar actos sin su presencia, indica también la sujeción de la mujer. Sin la licencia del marido esta no podía "presentarse en juicio, repudiar ninguna herencia que le corresponda por testamento o ab intestato, ni aceptarla sino a beneficio de inventario, tampoco celebrar contrato ni cuasi contrato alguno ni apartarse de los ya celebrados" (Galván, 1851, t. I, p. 40; Rodríguez de San Miguel, 1991, t. II, p. 390). De hecho, según algunas fuentes de derecho, si la mujer era menor de 25 años, además de la autorización del cónyuge, requería, para contratar de algún modo sus bienes, de un curador nombrado por el juez. La razón que sustentó lo anterior fue que "la emancipación que adquiere [la mujer] por el matrimonio sólo sirve para que su padre no tenga poder sobre ella ni vuelva a tenerle después que enviude, mas no para que sea reputada mayor y capaz de gobernarse" (Escriche, 1993, p. 458).

En medio del cúmulo de restricciones descrito, la Ley Lerdo siguió una política ciega o neutral respecto al género. Retomo el término de "política ciega o neutral” de Diana Deere y Carmen León, autoras que establecen que el acceso a la propiedad por las mujeres - tema de su obra- se ha visto impedido por mecanismos de carácter legal, cultural, estructural e institucional. Con base en esta afirmación, ambas advierten que cuando la ley no contiene algún mecanismo que favorezca o excluya a algún género, puede hablarse de política ciega o neutral. Ni en sus considerandos, ni en los 35 artículos que forman su redacción general, ni en los 32 de su reglamento -de 30 de julio de 1856-, el decreto de desamortización estableció restricciones o facilidades relacionadas con la categoría de género que impidieran o facilitaran a las mujeres adjudicar una propiedad (Deere y León, 2002, pp. 4, 6, núm. 9).

Según su artículo $1^{\circ}$, la Ley Lerdo favoreció la adjudicación por los arrendatarios o inquilinos y censualistas de los edificios y tierras que las corporaciones administraban como propietarias. Los artículos $4^{\circ}$ y $5^{\circ}$ contemplaron que, en caso de existir más de un inquilino en una finca urbana, la propiedad se adjudicaría a quien pagara mayor renta o al más antiguo. En el caso de las fincas rústicas la adjudicación se otorgaría en la parte que cada individuo tuviera arrendada. También se indicó que las propiedades que no se encontraran arrendadas se adjudicarían al mejor postor en almoneda pública (Dublán y Lozano, 2004, t. viII, núm. 4715). 
Los arrendatarios podrían hacerse con el bien del que se tratara en el término de tres meses, para ello debían reconocer el valor correspondiente a la renta que pagaban, calculada como rédito a $6 \%$ anual. Por ejemplo, si una finca pagaba 600 pesos anuales de renta, el valor de la finca era de 10000 pesos $(600 / 6 \times 100)$. El artículo $7^{\circ}$ del decreto señaló que los adjudicatarios podrían redimir el total del censo en el momento que desearan; es decir, el valor del inmueble se constituyó como una deuda a plazo redimible o perpetuo "por no tener un término señalado y no acabarse con el tiempo" (Escriche, 1993, p. 107). También lo podrían hacer en pagos de 250 pesos si el valor de la propiedad fuera menor a 2000 pesos, pero si se excedía este monto los pagos parciales tendrían que ser de 1000 pesos (Dublán y Lozano, 2004, t. viII, núm. 4715). Como ha señalado Jan Bazant, la ley generó un incentivo a los posibles adjudicatarios al incrementar el porcentaje de la capitalización de la renta del tradicional 5 al $6 \%$, lo que generó un descuento de $16.67 \%$ sobre el valor de los inmuebles (Bazant, 1972, p. 193).

Una revisión de los pagos que debían satisfacerse al adjudicar una propiedad permite advertir la importancia de la medida para el erario y el dinamismo de la esfera económica en la coyuntura de la desamortización.

\section{LA ALCABALA O TRASLACIÓN DE DOMINIO Y LA CONSOLIDACIÓN DEL DERECHO DE PROPIEDAD}

La Ley Lerdo se tradujo en la obtención de un beneficio económico inmediato para el depauperado erario público. En el año de 1855, la traslación de dominio ingresó al erario apenas 6213.66 pesos, mientras que, en 1856, con base en los procedimientos de desamortización, el monto obtenido por el mismo derecho fue de 675308.73 pesos, diez veces más que lo recaudado un año antes (Lerdo de Tejada, 1857, p. 535).

Las adjudicaciones requirieron pagar dos gravámenes: el derecho de traslación del dominio y la contribución de tres al millar. La traslación de dominio gravó, en términos generales, la transmisión de la propiedad inmueble y los derechos con ella relacionados, recibió también el nombre de alcabala, es decir, fue un impuesto a los actos económicos de la adjudicación y la venta (Dublán y Lozano, 2004, t. viII, núm. 4647).

En el México independiente, la traslación fue un gravamen que perteneció a las rentas generales de la nación. En febrero de 1856, un decreto insistió en lo anterior y respetó la tarifa establecida de $5 \%$. Este decreto fue importante, primero, porque admitió que la mitad del pago del derecho se satisficiera mediante bonos de la deuda nacional consolidada, interior o exterior. Segundo, porque declaró libres del impuesto a los bienes amortizados "siempre que entren a la circulación del comercio”. Cabe advertir que la propia Ley Lerdo modificó en su artículo 32 esta exención. Por último, la medida contempló que aun cuando los arrendatarios renunciaran a su derecho como adjudicatarios para realizar una compra convencional, el pago de la alcabala o de la traslación de dominio, según el artículo $10^{\circ}$, no podría ser menor al que diera "la suma de arrendamientos conforme a la ley” (Dublán y Lozano, 2004, t. viII, núms. 4647, 4715, 4734).

Si bien la traslación de dominio es un derecho y no un impuesto -el derecho es un gravamen establecido en una ley por servicios que presta el Estado en sus funciones, mientras que al impuesto subyace un hecho generador del tributo establecido sobre quienes se ubican en el hecho imponible, sin recibir prestación inmediata-, en la coyuntura que representó la ley el 25 de junio de 1856, el derecho de traslación fue un gravamen con una abierta intencionalidad fiscal, en el sentido de la obtención del tributo (Carrasco, 2003). 
El derecho se recaudó, durante 1856, por la Administración Principal de Rentas en el caso del Distrito Federal; por las Jefaturas Superiores de Hacienda en el caso de las capitales de los estados y territorios, y por las administraciones de correos en las cabeceras de partido.

Según el decreto del 25 de junio de 1856, y su reglamento del 30 del siguiente mes, "las adjudicaciones y remates deber[í]an hacerse dentro del término de tres meses, contados desde la publicación de esta ley en cada cabecera de partido". Todas las "traslaciones de dominio" de fincas rústicas y urbanas "causar[í]an la alcabala de cinco por ciento”. El pago de la misma se haría,

[...] una mitad en numerario y la otra en bonos consolidados de la deuda interior, por las adjudicaciones que se verifiquen dentro del primer mes: dos terceras partes en numerario y una tercera en bonos por las que se hagan en el segundo; y sólo una cuarta parte en bonos y tres cuartas en numerario por las que se practiquen dentro del tercero. Después de cumplidos, los tres meses, toda la alcabala se pagará en numerario (Dublán y Lozano, 2004, t. viII, núm. 4715).

La posibilidad de satisfacer el pago de la traslación con bonos de la deuda consolidada favoreció la participación de un mayor número de adjudicatarios, quienes con relativa facilidad podían recurrir al devaluado mercado de bonos y obtener del gobierno el reconocimiento de su valor nominal.

La Ley Lerdo expresó con mucha claridad su objetivo político pues, conforme al artículo $34^{\circ}$ del decreto de desamortización, del producto de la traslación se tomaría un millón de pesos para los gastos urgentes del gobierno: "la capitalización de los retiros, montepíos y pensiones civiles y militares, así como [...] la amortización de alcances de los empleados civiles y militares en actual servicio" (Dublán y Lozano, 2004, t. vIII, núm. 4715).

Como se revisará más adelante, este pago se consideraría un factor de peso para adquirir la propiedad de las fincas y terrenos cuando las adjudicatarias originales y alguien más reclamaron derechos sobre el mismo bien, debido a la confusión que generó la anulación de la medida a raíz de la guerra civil y la entrada de los bienes al proceso de nacionalización, una vez que esta fue promulgada.

\section{AdJUDicatarias y PROPIETARIAS}

La premura económica fue un factor para que la desamortización observara una política ciega respecto al género. En este sentido, y de acuerdo con Joan W. Scott (1996), "los cambios en las relaciones de género pueden ser impulsados por consideraciones de necesidades de Estado” (p. 296); es decir, el Estado genera la posibilidad de cambio sin ser ese su objetivo prioritario. La Ley Lerdo estaba preocupada por allegar recursos al erario público, no por cuestionar las limitaciones impuestas a las mujeres por los cuerpos de derecho y, en consecuencia, desestimarlas. De hecho, debe subrayarse que aun cuando la Ley Lerdo fue una ley ciega al género, hubo otros ordenamientos, como se expresó en el apartado anterior, que normaban limitaciones para las mujeres respecto al ejercicio de la propiedad. Lo anterior, sin embargo, no deja de reflejar un clima de opinión propicio, pese a los temores, para que se llevaran a cabo cambios; un sector importante de la sociedad no vería mal que las mujeres accedieran a la propiedad por el hecho de ser arrendatarias (Cervantes, 2004; Staples, 2009). 
Ahora bien, la inestabilidad que acompañó al gobierno sustituto de Comonfort limitó la credibilidad de la medida; de ahí el bajo número de adjudicaciones en julio. La posibilidad de perder las propiedades por los remates al concluir el plazo contemplado por la ley modificó el ritmo de las adjudicaciones que se incrementaron notoriamente durante los últimos días de septiembre.

La Ley Lerdo, como se dijo antes, se abrogó en enero de 1858 y la nacionalización sobre los bienes eclesiásticos se promulgó en julio de 1859, lo que afectó a buen número de los bienes adjudicados, como se expondrá más adelante. Al concluir la Guerra de Reforma el clima de incertidumbre respecto a la propiedad de los bienes era general, por lo que el 15 de febrero de 1861 se publicaron unas "Aclaraciones sobre las leyes de desamortización y nacionalización". En ellas, la postura inicial ciega al género fue modificada. En su artículo $5^{\circ}$ se lee que eran adjudicatarias legítimas: "las solteras, viudas o huérfanas que, aunque hayan vuelto la escritura con nota de conformidad, y aunque hayan sacado el certificado de devolución de alcabala, llevaban más de cinco años de vivir en la casa cuya escritura de adjudicación devolvieron, con tal que se trate de una sola finca” (Dublán y Lozano, 2004, t. Ix, núm. 5198, p. 54).

De igual modo, el artículo $6^{\circ}$ de este decreto favoreció a las mujeres que eran menores de edad o lo hubieran sido al momento de hacerse la devolución de los bienes, en lo que constituye un artículo pensado para favorecer a las mujeres que realizaron transacciones al amparo de la ley de 1856.

Es claro que en 1861 la legislación republicana mostró un interés particular por favorecer a las mujeres. Los procedimientos legales seguidos por las adjudicatarias que lograron la propiedad de los bienes y sus herederos muestran también que, entre 1863 y 1867, bajo la Regencia y el Imperio, aquellos fueron avalados por las autoridades correspondientes (Pani, 2004).

Jan Bazant ha estimado que gracias al decreto de febrero de 1861 "los adjudicatarios y rematantes originales volvieron en su mayor parte a la posesión de sus fincas". Añade que "la continuidad entre 1856 y 1861 dio confianza a la masa de los adjudicatarios en la fuerza del gobierno" (Bazant, 1972, p. 205). Sin embargo, de las 353 adjudicatarias que se documentaron en el AGNGM, únicamente 100 redimieron o pagaron capitales para obtener eventualmente la propiedad de los bienes hacía años adjudicados, y tan sólo 29 mujeres lograron adquirir su propiedad.

Lo anterior se llevó a cabo a través de 104 operaciones, $31.23 \%$ del universo total de adjudicaciones hechas por mujeres en 1856. Cuatro adjudicatarias -Trinidad Espinoza, Rafaela Murguía, Mariana Gual de Mateos, una de las grandes propietarias de la época, y Albina Azpilcueta, muy activa en la economía de la urbe entre 1851 y 1860- satisficieron pagos sobre más de una propiedad.

Además, en una Memoria... redactada por el responsable de la Oficina Especial de Desamortización en el Distrito Federal durante 1861, se encuentran 124 casos más de los que están documentados en el AGNCM. Debe distinguirse a estas 124 mujeres de las primeras 100 por las siguientes razones. Primera, la fuente no indica a qué corporación perteneció el bien redimido y dónde se encontró. Segunda, se omite también cuál fue el valor de la propiedad, y aunque este dato podría estimarse con el monto de la redención o pago de gravámenes, el propio testimonio reconoce que en algunos casos estos pagos fueron parciales. Tercera, dado que los nombres de estas adjudicatarias no se encuentran en el archivo, es un hecho que se trató de mujeres que lograron adquirir los derechos de propiedad luego de diciembre de 1856. En gran medida, como resultado de los desistimientos de los adjudicatarios originales, y también, por el cúmulo de propietarios inciertos que en determinado momento produjo la abrogación de la Ley Lerdo en 1858. 
En diez de esos 124 casos las mujeres -Dolores Ortiz, Soledad Ramírez de Domínguez, Agapita Martínez, María de Jesús del Villar de Espinosa, María de Jesús de la Peña, Juana Sánchez Barquera, María Dionisia Arrazola, Juliana Téllez, Guadalupe León de Abad y María de Jesús Ruiz- actuaron representando el interés de alguien más, por lo general un hijo menor de edad o una testamentaría. Lo anterior es importante pues subraya cómo los procesos de desamortización y nacionalización permitieron que las mujeres actuaran en el espacio público (Memoria, 1862, pp. 117, 128-129, 132, 135, 139-140).

Ahora, se describirán algunos de los argumentos que, con base en la legislación favorable a su género, las adjudicatarias originales y sus herederos emplearon en sus intentos por recuperar los bienes adquiridos por la Ley Lerdo; sobre estos procesos, a veces fallidos, se tiene noticia gracias a las glosas añadidas a los protocolos notariales.

Uno de estos casos es el del inmueble adjudicado el 16 de septiembre de 1856 a Guadalupe Andrade. Para 1861 Guadalupe había muerto y su hermana Ignacia redimió a favor de su sobrino, el menor Carlos España y Andrade, la finca perteneciente al convento de Balvanera. Argumentó, con base en el artículo $7^{\circ}$ del decreto de 5 de febrero de 1861, que en la cancelación de la escritura realizada por su hermana no hubo consentimiento, sino "la simple sujeción a la llamada Ley de 28 de enero de 1858 ". ${ }^{1}$ La glosa añadida a la mayoría de las escrituras del universo de estudio inclina a señalar que la mayor parte de las cancelaciones se realizaron por esa vía lo que, en virtud del decreto de 5 de febrero de 1861, permitió posteriormente a muchas de las adjudicatarias realizar la redención del capital y conservar la propiedad (Dublán y Lozano, 2004, t. Ix, núm. 5198). No obstante, según una glosa en enero de 1866, luego de seguirse el juicio respectivo, la comisión segunda del Consejo de Estado del Imperio Mexicano determinó que la propiedad pertenecía a Manuel Buenrostro, quien subrogó el derecho de Guadalupe.

Las complicaciones del aparentemente sencillo procedimiento de redención son ilustradas por el caso de María Concepción Aguilar; ella expone las incertidumbres por las que atravesó más de un adjudicatario. El 15 de marzo de 1858 su apoderado canceló la adjudicación en virtud de la ley de 28 de enero de ese año. Pero, una vez que triunfó el partido liberal ella redimió la deuda -el 14 de marzo de 1861 - ante la Oficina Especial de Desamortización en el Distrito Federal. ${ }^{2}$

Cuando María renunció a la adjudicación, la propiedad fue denunciada en Veracruz por Eulalia Adoreu de Williams, a través de la Cía. E. Bernay de la que Eulalia fue socia. Como respuesta a la administración de Zuloaga en la capital del país, una resolución de 30 de agosto de 1858 había dispuesto que las fincas devueltas podrían denunciarse ante el gobierno constitucional en Veracruz; la medida incrementó la incertidumbre de los posibles propietarios (Gutiérrez, 1868, t. II, v. I, p. 792). Luego de seguir varios juicios, en 1865 el Consejo de Estado Imperial le reconoció los derechos a María en virtud de las sentencias pronunciadas por el juez tercero de lo civil, Antonio Aguado, el 6 de octubre de 1862 y el 26 de mayo de 1863, en primera y segunda instancias, respectivamente.

Los argumentos que la favorecieron fueron los siguientes. Primero, María Concepción expuso que era una mujer soltera. Segundo, que sólo se había adjudicado la propiedad que ocupó como inquilina. Y, tercero, que según el artículo $12^{\circ}$ de la ley de 13 de julio de 1859 , esta comenzó a

${ }^{1}$ Fondo Antiguo (en adelante FA), Adjudicación, Daniel Méndez (433), 16 de septiembre de 1856, vol. 2929, ff. 321330, Archivo Histórico de Notarías de la Ciudad de México (en adelante AGncm).

${ }^{2}$ La adjudicación se hizo por 8200 pesos. De manera que redimió 4920 en bonos y 3280 pesos en efectivo más réditos vencidos por 99.75, que dieron un total de 3 379.75. FA, Adjudicación, Remigio Mateos (436), 24 de septiembre de 1856, vol. 2933, ff. 405-408, AGNCM. 
regir sólo cuando fue publicada oficialmente en cada lugar (Dublán y Lozano, 2004, t. viII, núm. 5054). Además, debía considerarse que el plazo señalado por dicha ley para hacer las redenciones se prorrogó 40 días más por el decreto de 21 de febrero de 1861. En la ciudad de México la publicación de la ley de 13 de julio se llevó a cabo el 28 de diciembre de 1860, de manera que Concepción actuó en tiempo y forma, es decir, dentro del plazo autorizado por la ley (Dublán y Lozano, 2004, t. IX, núms. 5236 y 5237; Gutiérrez, 1868, t. II, v. I, II, p. 332).

Llama la atención uno de los argumentos expuestos en la segunda instancia. Según esa sentencia, a diferencia de la denunciante, quien "no arriesgó nada”, Concepción, como adjudicataria original, había hecho el pago de alcabala y no pidió su devolución para conservar su derecho al inmueble, por lo que sin duda a ella era a quien le correspondía la propiedad. ${ }^{3}$

El razonamiento del juez habla de la percepción que los adjudicatarios tuvieron en su momento, esto es, cualquier cambio de gobierno podría significar la pérdida del patrimonio recién adquirido. El pago de la alcabala y el no haber solicitado su restitución cuando se abrogó la Ley Lerdo en enero de 1858, fue el riesgo que María Concepción y otros adjudicatarios corrieron. Otro aspecto de este caso resulta relevante: el gobierno constitucional rechazó -por medio del decreto de 11 de mayo de 1865 y la circular de la misma fecha- las revisiones ordenadas por el gobierno de Maximiliano; sin embargo, no hay una glosa posterior en la escritura de Concepción que haya revertido la decisión imperial. Maximiliano había ordenado la revisión de la desamortización y nacionalización de los bienes eclesiásticos por medio del decreto de 26 de febrero de 1865 , decreto que fue reglamentado días después, el 9 de marzo. Ambos gobiernos parecen haber coincidido en su defensa a los derechos de propiedad creados por la desamortización (García-Ugarte, 2010, t. II, pp. 1154-1156; Gutiérrez, 1868, t. II, v. II, pp. 683-697).

Aunque los documentos no refieren las razones por las que el Consejo de Estado del Imperio falló a favor de las herederas de Mariana Jiménez de Padilla - María de los Ángeles, Mariana, Remedios, Piedad y Guadalupe Padilla Jiménez-, es factible suponer que una legislación favorable al género, la creada en 1861, orientó la determinación de las instancias revisoras. A Mariana le había sido adjudicada la casa que arrendó al convento de Santa Teresa la Antigua. El 15 de septiembre de 1865, luego de revisar el expediente promovido por sus hijas, se indicó que la adjudicación era subsistente, pese a que la propiedad había sido denunciada en Veracruz, durante 1861, por un individuo de nombre Francisco Lazo Estrada. ${ }^{4}$

El artículo $15^{\circ}$ de la Ley de Nacionalización dispuso restituir las dotes a las monjas que voluntariamente decidieran abandonar el claustro (Dublán y Lozano, 2004, t. viII, núm. 5053, pp. 681682 y t. Ix, núm. 5187, p. 32). De este modo, la articulación entre desamortización y nacionalización hizo que algunas de las adjudicatarias originales participaran en el funcionamiento de la compleja economía estatal, más allá de la satisfacción del pago de los gravámenes (Chowning, 2006). Por glosa del 8 de julio de 1862 sabemos que Guadalupe Altamirano había pagado ante el interventor general de los conventos de señoras religiosas los 13600 pesos en que se había adjudicado, en septiembre de 1856, la finca que arrendaba al convento de la Antigua Enseñanza. Con esa cantidad se cubrieron las dotes de las madres María Dolores de la Fuente, María de la Luz Velázquez y María Trinidad Romero; los 1600 pesos restantes se emplearon en satisfacer la de María de la Paz Carrera, todas religiosas del convento al que perteneció la propiedad. ${ }^{5}$

${ }^{3}$ FA, Adjudicación, Remigio Mateos (436), 24 de septiembre de 1856, vol. 2933, ff. 405-408, AGNCM.

${ }^{4}$ FA, Adjudicación, Antonio Ferreiro (245), 10 de septiembre de 1856, vol. 1558, ff. 59r-60r, AGNCM.

${ }^{5}$ FA, Adjudicación, Antonio Ferreiro (245), 25 de septiembre de 1856, vol. 1558, ff. 181r-184, AGNCM. 
Otro caso en el que las adjudicatarias se involucraron en el funcionamiento de la economía estatal fue el de Josefa Álavez de Tamariz. Según una glosa del 26 de abril de 1859, a través del ministerio de Fomento, el gobierno otorgó, el 13 de abril de ese año, a Thomas Horncastle la redención de los 2000 pesos que Josefa reconocía a la Escuela de Agricultura por la adjudicación que realizó en 1856. Horncastle era un prestamista del gobierno -le había bridado un préstamo de 300000 pesos-. La glosa indica que si Horncastle no obtenía la redención del capital en seis meses, adquiriría la propiedad de la casa ubicada en el número 9 de la calle del Coliseo y podría disponer de su venta. ${ }^{6}$

Mariana Tamariz de Díaz, hija de la adjudicataria y su albacea, no pudo satisfacer el capital y consintió en que se realizara la venta. Esta se llevó a cabo el 10 de julio de 1861 por el apoderado de Horncastle, Isidoro de la Torre. El monto redimido sólo cubría una mínima parte de lo que se debía al acreedor; este prestamista contó con otros cinco bienes adjudicados a mujeres. Lo anterior muestra cómo los bienes adjudicados se volvieron una garantía para el pago de capitales que habían sido dados en préstamo por particulares al gobierno. ${ }^{7}$

Las dificultades para conocer el destino de los bienes ya eran evidentes en la época. Una glosa, añadida al protocolo de la adjudicación celebrada por Manuela Zozaya, advirtió que la imprecisión con que se asentaban los datos de la redención causaba confusiones. ${ }^{8}$ Las 29 adjudicatarias que, a través de 31 adjudicaciones $(9.30 \%$ de las 333$)$, obtuvieron "el dominio libre y absoluto" de las fincas se encuentran enlistadas en el cuadro 1.

Existen diferencias en las adjudicaciones, tres de las 29 fueron parte de familias de grandes propietarios de la época y parecen haber contado con capitales propios y bastante autonomía, se trata de Guadalupe Lelo de Larrea, María de Jesús Gómez de la Cortina y Loreto Vivanco de Morán. Es posible que también hubiera alguna relación entre Anna Vivanco y la familia a la que perteneció Loreto, pero no hay elementos suficientes para señalar el parentesco más allá de la coincidencia en el apellido. Sólo Carmen Vilela parece haber sido extranjera, casada con un español.

Relacionadas con algún personaje de la clase política y beneficiadas por esa relación estuvieron cuatro adjudicatarias: Ignacia Martínez, Candelaria Cárdenas, Soledad Castro de Mejía y Leocadia Ruano y Saviñón. Respectivamente, ellas estuvieron emparentadas consanguínea o políticamente con Leandro Valle, José María Zerecero, Francisco Mejía Escalada y Francisco Schiaffino. Otras mujeres que fueron beneficiadas por su relación con las esferas políticas fueron María Caso, la esposa de Guillermo Prieto y Mercedes Urquiaga de Lerdo de Tejada, cónyuge de Miguel Lerdo de Tejada, de quien se hablará más adelante. ${ }^{9}$

Tan sólo cinco de las 29 mujeres adjudicaron bienes de corporaciones civiles, en mayor número aquellas con fines religiosos y de asistencia social, el resto lo hicieron a corporaciones eclesiásticas.

\footnotetext{
${ }^{6}$ FA, Adjudicación, Antonio Ferreiro (245), 20 de septiembre de 1856, vol. 1558, ff. 121-123, AGNCM.

7 FA, Adjudicación, José Querejazu (550), 19 de septiembre de 1856, vol. 3732, ff. 306r-311, AGNCM.

${ }^{8}$ FA, Adjudicación, José María Ramírez (612), 9 de septiembre de 1856, vol. 4133, ff. 149r-153, AGNGM.

${ }^{9}$ FA, Adjudicación, Manuel de Madariaga (431), 16 de diciembre de 1856, vol. 2912, ff. 622-626. Adjudicación, Remigio Mateos (436), 26 de agosto de 1856, vol. 2933, ff. 162r.-166r., AGNCM.
} 


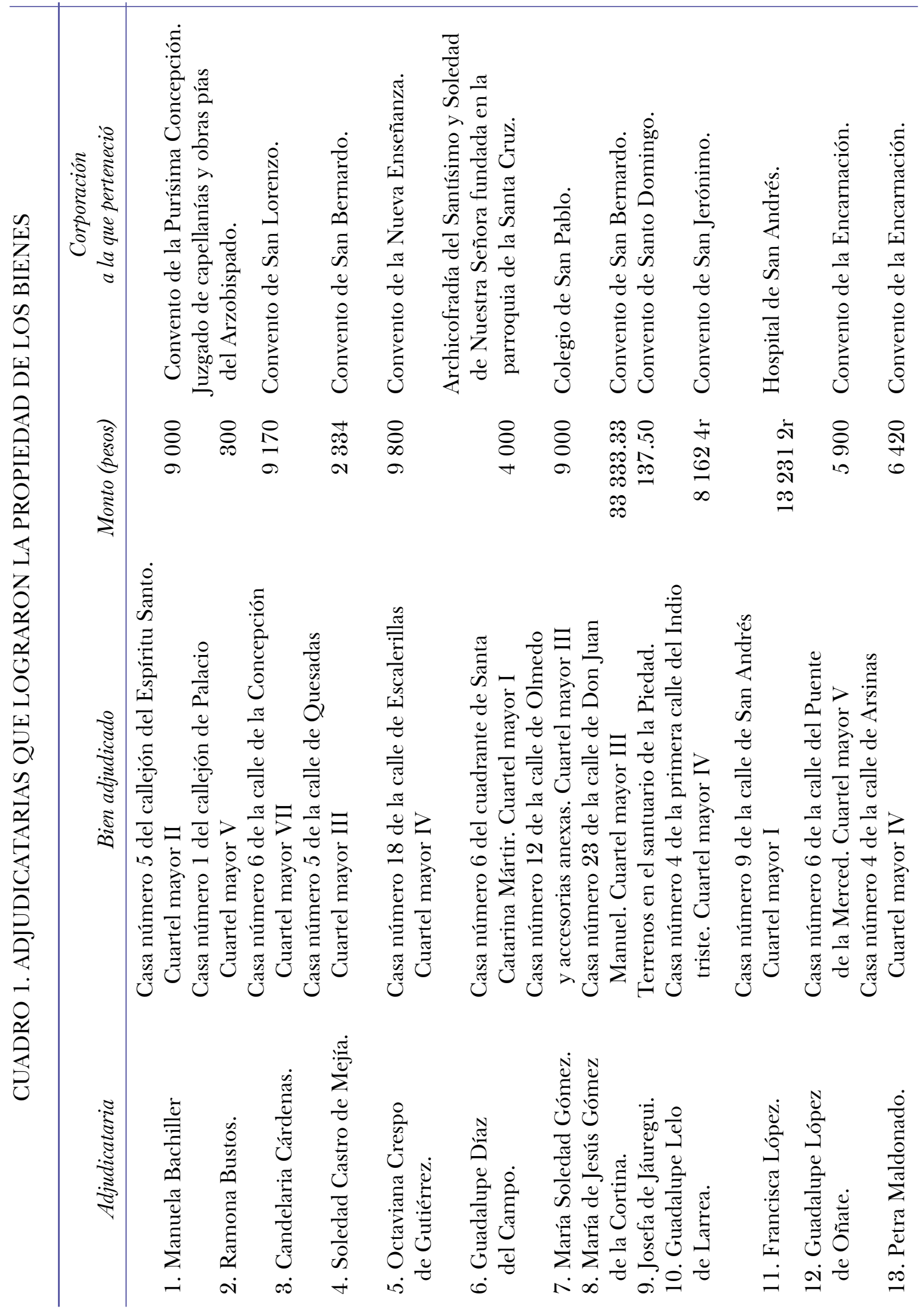



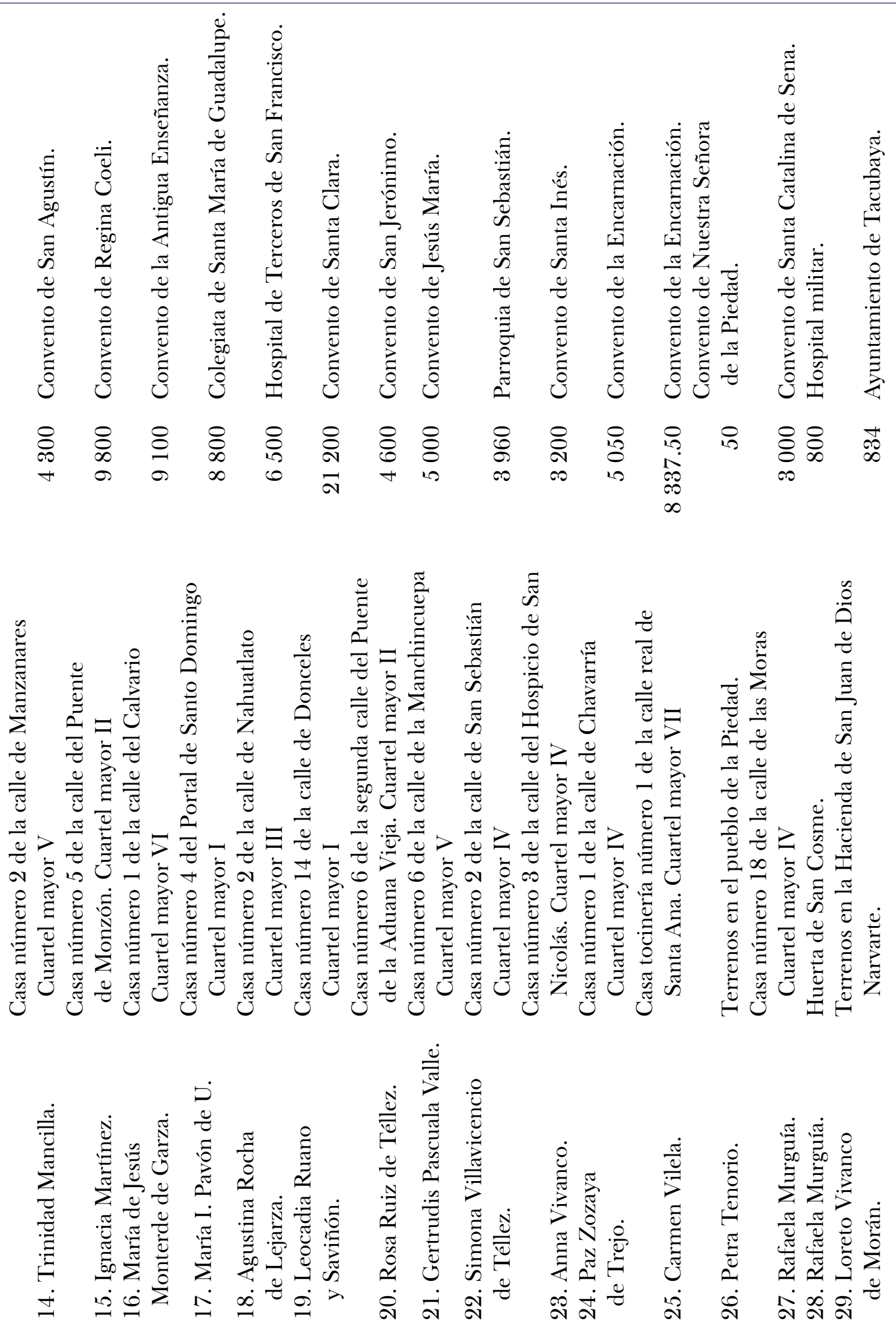


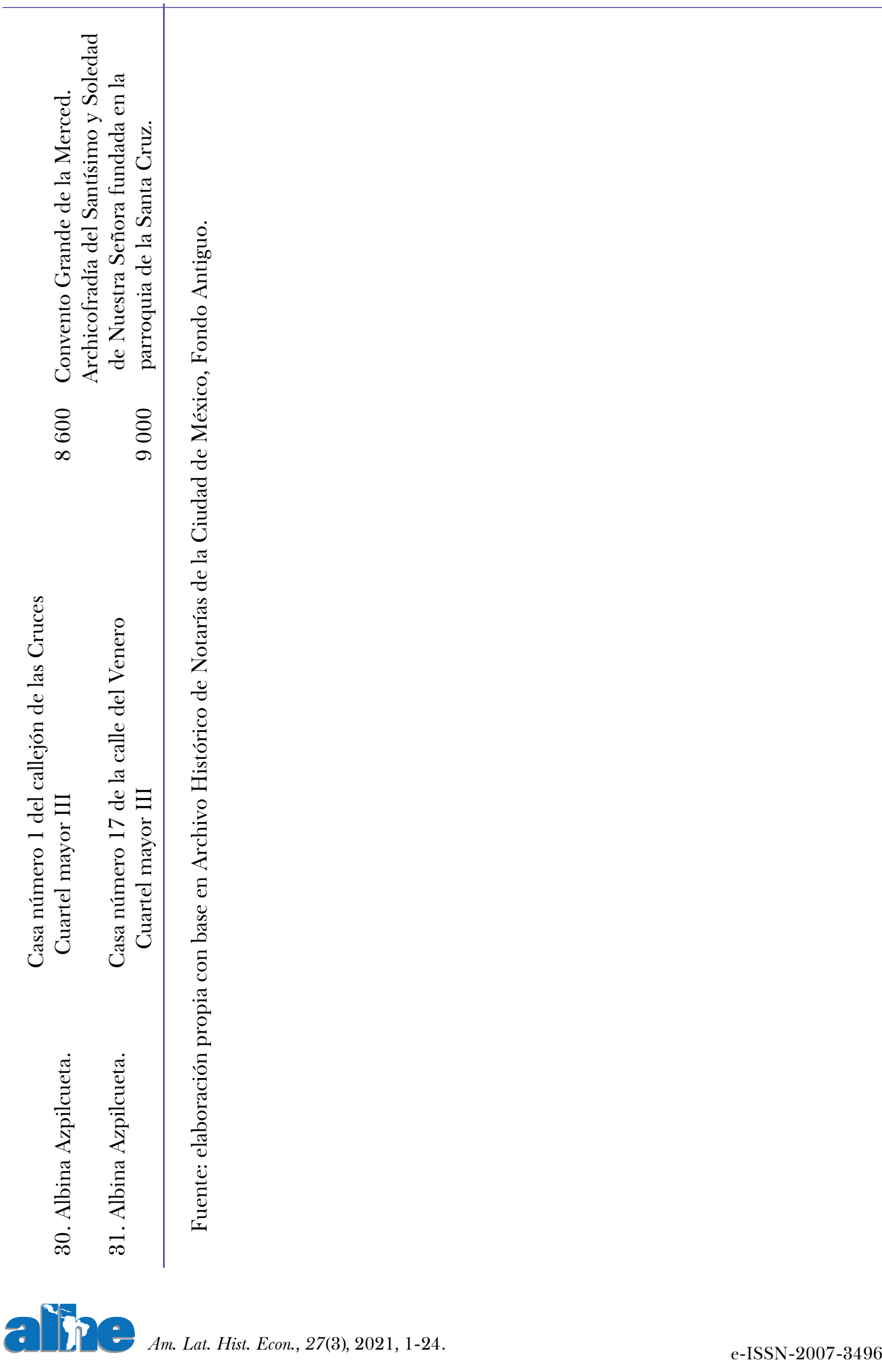


Dos adjudicatarias, Guadalupe Lelo de Larrea y María I. Pavón de U., adjudicaron en falsedad en principio, es decir, con el objetivo de mantener en resguardo la propiedad de las corporaciones, y modificaron su perspectiva al paso del tiempo. El cambio de perspectiva debió deberse a varios factores. Influiría el que en 1856 el arzobispo De la Garza pidiera al gobierno mexicano una moratoria de tres meses para que, en ese lapso, se negociara la desamortización directamente con la Santa Sede. Esta postura, como ha señalado Pablo Mijangos, dio a entender que la compra de bienes del clero no era un mal absoluto, sino una controversia jurídica que podía resolverse por la vía de una negociación diplomática sin implicar sanciones espirituales de mayor gravedad (Mijangos, 2018a, pp. 185-186). Posteriormente, el decreto de febrero de 1861, favorable para las adjudicatarias originales y el reconocimiento del segundo imperio a la desamortización y la nacionalización, contribuiría a cambiar la postura original de ambas adjudicatarias.

En 27 de los 31 casos, los bienes de estas mujeres se encontraron en los cuarteles centrales de la ciudad, principalmente los cuarteles mayores III y IV (véase mapa 1). Esto afirma que las adjudicatarias de propiedad urbana se vieron más favorecidas que las de propiedad rural; sólo cuatro adjudicatarias conservaron bienes que se encontraron fuera de la traza de la urbe: Josefa de Jáuregui, Petra Tenorio, Loreto Vivanco de Morán y Rafaela Murguía.

La ausencia de datos en los protocolos ha impedido dar un seguimiento a todas las propiedades que las adjudicatarias adquirieron en las corporaciones civiles; Melchora Sánchez de Padilla y Loreto Vivanco de Morán conservaron los bienes adjudicados que pertenecieron a las parcialidades de Nonoalco y al Ayuntamiento de Tacubaya, respectivamente. Faustino Galicia, como administrador de las parcialidades, le adjudicó a Melchora un potrero en San Miguel Nonoalco. El terreno fue valuado en 2000 pesos. En noviembre de 1876 se anotó que la adjudicación subsistía, con base en un protocolo del Ayuntamiento firmado el 10 de octubre de ese año por la comisión de Hacienda del municipio de la ciudad, pero no se habló de redención ni se dieron más datos. ${ }^{10}$

Hay que tener presente que algunas adjudicatarias celebraron protocolos por más de un bien. Ellas fueron Albina Azpilcueta, Paz Zozaya de Trejo, Carmen Vilela y Rafaela Murguía. Creo que las cuatro muestran el valor que, para algunos adjudicatarios, tuvo la Ley Lerdo como medio para adquirir una propiedad. Aunque ninguna figuró como miembro de la clase de grandes propietarios que ha identificado María Dolores Morales (1995), cabe insistir en que Albina Azpilcueta fue una mujer sumamente activa desde el punto de vista económico entre 1851 y 1860.

Un elemento que destaca es que las fincas y terrenos cuya propiedad fue adquirida por las 29 adjudicatarias se encontraron dentro de la media del valor de los 355 bienes adjudicados en 1856 , es decir, las propiedades que fueron de los 7501 a los 10000 pesos, lo que parece indicar que fueron las mujeres de una clase media emergente las que pudieron aprovechar de mejor manera la coyuntura del decreto de desamortización (véase cuadro 2).

Ahora bien, si las comparamos entre sí el proceso de adquisición tuvo tiempos bastante disímiles. Gertrudis Pascuala Valle satisfizo en abril de 1861 los 5000 pesos que importó la redención de la casa que adjudicó al convento de Jesús María, constituyéndose en el acto en propietaria; incluso contó con un descuento de $25 \%$ sobre el monto que satisfizo en efectivo (2 000 pesos que quedaron en 1 500). ${ }^{11}$ El 21 de enero de 1861, Soledad Castro de Mejía redimió la propiedad que se había adjudicado y para el 7 de mayo de ese mismo año tenía "el dominio libre y absoluto

${ }^{10}$ Sobre Faustino Galicia, véase Lira (1983, p. 170); FA, Adjudicación, José Querejazu (550), 25 de julio de 1856 , vol. 3732, ff. 161r-165, AGNCM.

${ }^{11}$ FA, Adjudicación, Remigio Mateos (436), 8 de agosto de 1856, vol. 2933, ff. 108r-112, AGNCM. 


\section{MAPA 1. CIUDAD DE MÉXICO, 1856}

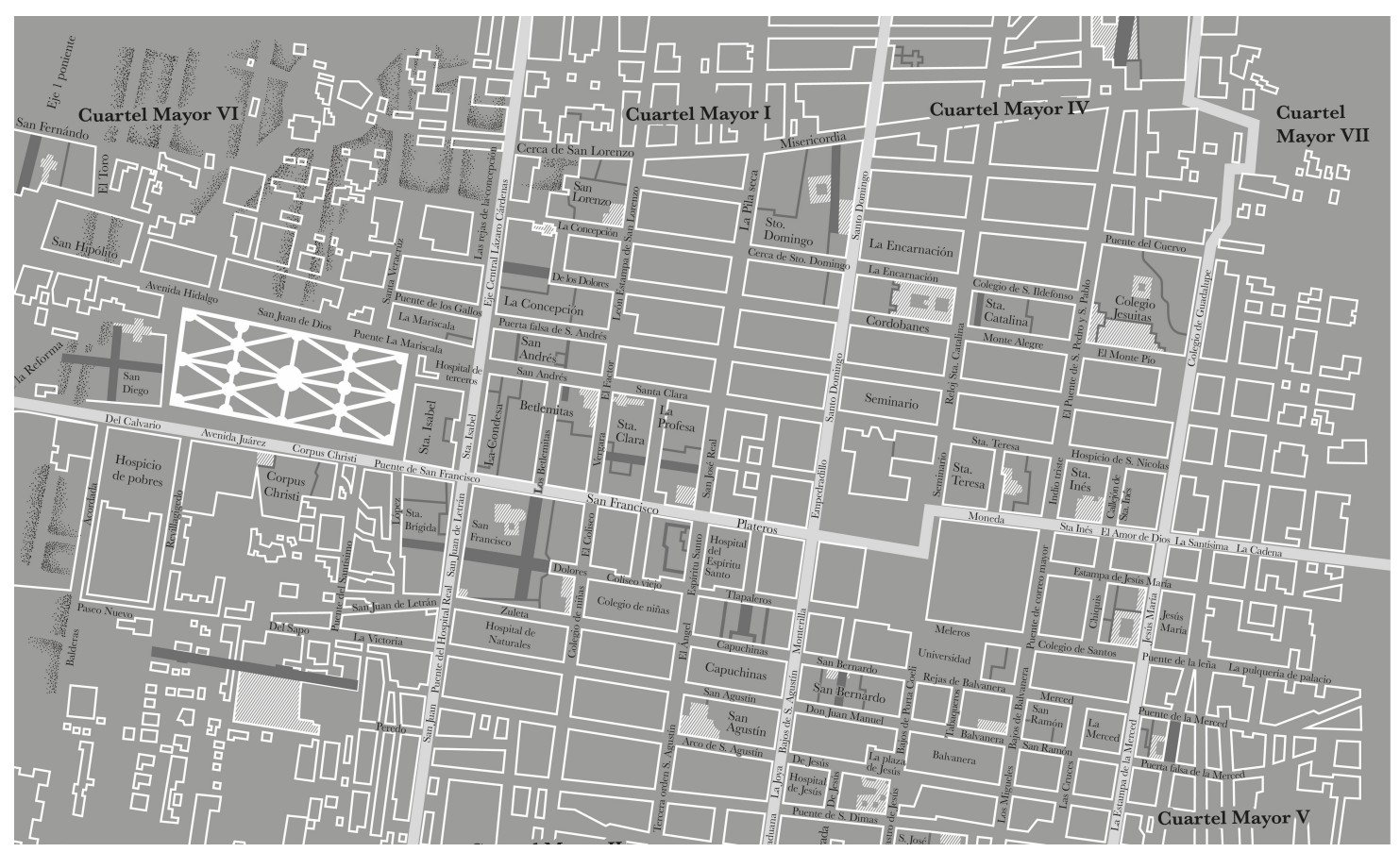

Fuente: Morales (1995, pp. 155-190); Lombardo de Ruiz et al. (2009); Archivo Histórico de Notarías de la Ciudad de México, Fondo Antiguo.

de la mencionada finca". ${ }^{12}$ Octaviana Crespo de Gutiérrez redimió su adeudo el 16 de marzo de 1861 y un año después, el 18 de julio de 1862, gozaba ya de la propiedad de la casa que había adjudicado al convento de la Nueva Enseñanza. ${ }^{13}$ En agosto de 1862, Agustina Rocha de Lejarza gozaba de la propiedad de la casa que perteneció al patrimonio del Hospital de Terceros de San Francisco. ${ }^{14}$

No todas las adjudicatarias lograron obtener con tanta presteza la propiedad. En mayo de 1863, Anna Vivanco hizo lo propio con la casa ubicada en el número 3 de la calle del Hospicio de San Nicolás. ${ }^{15}$ Ese año, también Albina Azpilcueta satisfizo las redenciones de dos propiedades, una del convento de la Merced y otra de la archicofradía del Santísimo y Santa Cruz, que importaron 12313 pesos. ${ }^{16}$ Guadalupe López de Oñate logró satisfacer su adeudo en septiembre de 1864, tres años después de haber hecho la redención. ${ }^{17}$

En octubre de 1867, ya ante la Administración de Bienes Nacionalizados, creada en agosto de ese año para culminar la nacionalización de los bienes clericales, María Soledad Gómez consiguió cancelar la deuda de la casa que originalmente arrendó al colegio de San Pablo. Un mes después,

12 FA, Adjudicación, Remigio Mateos (436), 17 de diciembre de 1856, vol. 2934, ff. 828r-837, AGNCM.

${ }^{13}$ FA, Adjudicación, Remigio Mateos (436), 22 de septiembre de 1856, vol. 2933, ff. 373-379, AGNCM.

14 FA, Adjudicación, Manuel Aristegui (39), 24 de septiembre de 1856, vol. 296, ff. 62-66, AGNCM.

${ }^{15}$ FA, Adjudicación, José de Jesús Piña (534), 26 de septiembre de 1856, vol. 3580, ff. 28r-33, AGNCM.

${ }^{16}$ FA, Adjudicación, Remigio Mateos (436), 18 de septiembre de 1856, vol. 2933, ff. 302-305, AGNCM.

17 FA, Adjudicación, José Villela (725), 24 de septiembre de 1856, vol. 4391, ff. 103r.-108, AGNCM. 
CUADRO 2. MONTOS DE LOS BIENES ADJUDICADOS

\begin{tabular}{|c|c|c|}
\hline $\begin{array}{c}\text { Rango } \\
\text { (en pesos) }\end{array}$ & Bienes adjudicados & Porcentaje \\
\hline 0 а 50 & 33 & 9.32 \\
\hline 51 a 100 & 3 & 0.84 \\
\hline 101 a 500 & 10 & 2.82 \\
\hline 501 a 1000 & 9 & 2.54 \\
\hline 1001 a 3000 & 36 & 10.16 \\
\hline 3001 a 5000 & 48 & 13.55 \\
\hline 5001 a 7500 & 55 & 15.53 \\
\hline 7501 a 10000 & 63 & 17.79 \\
\hline 10001 a 12500 & 34 & 9.32 \\
\hline 12501 a 15000 & 24 & 6.77 \\
\hline 15001 a 17500 & 10 & 2.82 \\
\hline 17501 a 20000 & 10 & 2.82 \\
\hline 20001 a 22500 & 7 & 1.97 \\
\hline 22501 a 25000 & 4 & 1.12 \\
\hline 25001 a 27500 & 4 & 1.12 \\
\hline 27501 a 30000 & 2 & 0.56 \\
\hline 30001 a 32500 & 1 & 0.28 \\
\hline 32501 a 35000 & 1 & 0.28 \\
\hline 35001 a 36000 & 1 & 0.28 \\
\hline Total & 355 & 99.89 \\
\hline
\end{tabular}

Fuente: Archivo Histórico de Notarías de la Ciudad de México, Fondo Antiguo.

Simona Villavicencio también satisfizo la deuda de la propiedad que perteneció al patrimonio de la parroquia de San Sebastián. ${ }^{18}$ En julio de 1868 Manuela Bachiller hizo lo mismo con la propiedad que formó parte del patrimonio del convento de la Concepción. ${ }^{19}$ Trinidad Mancilla satisfizo su deuda en $1870 .{ }^{20}$ Por su parte, Rafaela Murguía logró la propiedad de los dos bienes - una huerta en San Cosme y la casa ubicada en el número 18 de la calle de las Moras- que le fueron adjudicados un año después, en $1871 .^{21}$

La ley de nacionalización determinó que el monto en el que fueron valuados los bienes debía satisfacerse en 40 mensualidades. El 21 de febrero de 1861 el ministerio de Hacienda prorrogó "el término de cinco a nueve años" por medio de una circular (Dublán y Lozano, 2004, t. Ix, núm. 5237, p. 88). Las incertidumbres de los adjudicatarios eran reforzadas por las continuas disposiciones muchas veces opuestas. Por ejemplo, menos de un mes antes otra circular del mismo ministerio, la del 28 de enero de 1861, contempló la concesión de "gracias" temporales para la

${ }^{18}$ FA, Adjudicación, Agustín Pérez de Lara (Hda), 25 de septiembre de 1856, vol. 22, ff. 209r.-220. Adjudicación, Plácido de Ferriz (242), 29 de octubre de 1856, vol. 1489, ff. 267r.-275, AGNCM.

${ }^{19}$ FA, Adjudicación, Remigio Mateos (436), 17 de septiembre de 1856, vol. 2933, ff. 281r.-285, AGNCM.

${ }^{20}$ FA, Adjudicación, Alejandro Vázquez (727), 24 de septiembre de 1856, vol. 5038, ff. 89r.-96, AGNCM.

${ }^{21}$ FA, Adjudicaciones, Antonio Ferreiro (245), 2 y 3 de octubre de 1856, vol. 1558, ff. 219-222, AGNCM. 
satisfacción del capital, dos días después, el 30 de enero, fue anulada por una Suprema Orden que prohibió que se otorgara cualquier prórroga, para, como se ha indicado, conferirla finalmente el 21 de febrero (Gutiérrez, 1868, t. II, v. II, pp. 333-334). Parece que las adjudicatarias aprovecharon, como se verá enseguida, esa vacilación institucional. Los casos documentados perfilan que el gobierno nunca tuvo la capacidad para uniformar los criterios y sujetar a los mismos a las interesadas en obtener la propiedad de los bienes. El decreto del 13 de agosto de 1862 señaló que, de no redimirse los capitales ocho días después de promulgado este, el gobierno subrogaría los derechos de los deudores. Los testimonios permiten observar que si en algún momento la medida se ejecutó parece no haber operado en todos los casos (Gutiérrez, 1868, t. II, v. II, pp. 632-633).

Guadalupe Díaz del Campo redimió el capital adeudado conforme a la ley en marzo de 1861, para diez años después, el 16 de noviembre de 1871, satisfacer el total de la deuda y erigirse en propietaria. ${ }^{22}$ Un año después, en 1872, Leocadia Ruano y Saviñón y Rosa Ruiz de Téllez lograron acreditar la propiedad de las casas que se les adjudicaron y pertenecían al convento de Santa Clara y San Jerónimo, respectivamente. ${ }^{23}$ María de Jesús Gómez de la Cortina tardó 20 años en liquidar la deuda. La casa que ella arrendó al convento de San Bernardo en la calle de Don Juan Manuel es la mejor valuada del universo de estudio -36 666.30 pesos- ${ }^{24}$ María I. Pavón demoró más de 20 años en liquidar los capitales adeudados y, en el caso de Francisca López, ese también fue el plazo. ${ }^{25}$ A Petra Maldonado le tomó 35 años hacerlo. ${ }^{26}$

Hubo sanciones por no poder cumplir con los términos convenidos para satisfacer los adeudos, como se advierte en el protocolo de la adjudicación que hizo Ramona Bustos. En julio de 1861, Ramona liquidó la deuda en bonos -recuérdese que esta era por las ${ }^{3} / 5$ partes del monto de la redención- del corral que perteneció al juzgado de Capellanías y obras pías del arzobispado. ${ }^{27}$ El monto total de su propiedad fue de apenas 300 pesos, de los que correspondía satisfacer en bonos 180. Ramona tuvo que pagar una sanción de $50 \%$ del monto de los créditos al no haber cubierto en la fecha convenida el total de ese adeudo (Dublán y Lozano, 2004, t. Ix, núm. 5198, pp. 54-62.). ${ }^{28}$

Sin embargo, así como hubo sanciones, también hubo exenciones. Ana Michelet de Parrodi debió satisfacer 3360 pesos -las ${ }^{2} / 5$ partes- en efectivo al celebrar la redención de la casa que adjudicó. Como liquidó en el momento el capital gozó de un descuento de $25 \%$ sobre esa cantidad. ${ }^{29}$ A Ignacia Martínez le fue adjudicada por remate una casa que perteneció al convento de Regina Coeli. En febrero de 1861 su hijo, el general Leandro Valle, realizó la redención de capitales. Pocos meses después Valle murió fusilado por los conservadores, y en julio de 1861 el Congreso de la Unión decidió exentar a Ignacia del adeudo y otorgarle la propiedad del inmueble. ${ }^{30}$

22 FA, Adjudicación, Remigio Mateos (436), 22 de septiembre de 1856, vol. 2933, ff. 373-379, AGNCM.

${ }^{23}$ FA, Adjudicación, Francisco Pérez de León (533), 24 de diciembre de 1856, vol. 3572, ff. 780-782. Adjudicación, José Querejazu (550), 29 de octubre de 1856, vol. 3732, ff. 484-489, AGNCM.

${ }^{24}$ FA, Adjudicación, Antonio Ferreiro (245), 3 de septiembre de 1856, vol. 1558, ff. 49r.-51, AGNCM.

25 FA, Adjudicación, Francisco Pérez de León (533), 20 de septiembre de 1856, vol. 3571, ff. 216-219. Adjudicación, Manuel Orihuela (486), 4 de septiembre de 1856, vol. 3304, ff. 254r.-263, AGNCM.

${ }^{26}$ FA, Adjudicación, Antonio Ferreiro (245), 26 de noviembre de 1856, vol. 1558, ff. 254-255, AGNCM.

27 FA, Adjudicación, Joaquín Vigueras (723), 25 de septiembre de 1856, vol. 4920 bis, ff. 130-131, AGNGM.

28 FA, Adjudicación, Joaquín Vigueras (723), 25 de septiembre de 1856, vol. 4920 bis, ff. 130-131, AGNCM.

${ }^{29}$ Aclaraciones sobre las leyes de desamortización y nacionalización, 5 de febrero de 1861, en Dublán y Lozano (2004, t. IX, núm. 5198, pp. 54-62); FA, Adjudicación, Joaquín Vigueras (723), 22 de septiembre de 1856, vol. 4920 bis, ff. 87r.-89, AGNCM.

${ }^{30}$ FA, Adjudicación, Crescencio Landgrave (362), 6 de diciembre de 1856, vol. 2353, ff. 275r.-282, AGNCM. 
Otra mujer que fue beneficiada por una disposición gubernamental fue Mercedes Urquiaga de Lerdo de Tejada. Aunque en 1856 el adjudicatario de la propiedad fue el ministro de Hacienda, razón por la que ella no está incluida en el universo de estudio, en abril de 1861 el ministro de Gobernación, por orden presidencial, indicó a la Dirección General de los Fondos de Beneficencia Pública que la propiedad le fuera entregada a Mercedes, quien había quedado viuda. También se determinó que en compensación el ministerio de Hacienda debería entregar otra propiedad al hospital de Jesús, la corporación a la que perteneció el inmueble. ${ }^{31}$

Debo señalar que 23 de las 29 mujeres que lograron la propiedad de los bienes adjudicados celebraron, por lo menos, una operación más ante algún notario en la década que corrió de 1851 a 1860, es decir, la mayoría de estas adjudicatarias presentaron una actividad económica relacionada, al menos, con otra operación de compraventa. Destacaron por su presencia tres de las adjudicatarias: Albina Azpilcueta, Octaviana Crespo de Gutiérrez y María de Jesús Gómez de la Cortina, esta última identificada como una de las grandes propietarias y empresarias de la época (Morales, 1995, p. 199).

También debe advertirse que, al igual que en el caso de las adjudicatarias en falsedad, hubo quienes encontraron en el decreto del 25 de junio de 1856 una oportunidad excepcional para constituirse como propietarias. En este caso estuvieron seis adjudicatarias: Candelaria Cárdenas, María Soledad Gómez, Agustina Rocha de Lejarza, Rosa Ruiz de Téllez, Petra Tenorio y Petra Maldonado. No he podido localizar datos que me permitan conocer más sobre la procedencia social de estas; parece, en todo caso, que cumplieron con el ideal que se propuso la Ley Lerdo: extender el número de propietarios.

La inestabilidad política del periodo es una constante. En 1861 el partido liberal se había apropiado de nuevo de la ciudad de México; pero es un hecho, como se expuso, que los bienes adjudicados, devueltos a las corporaciones y posiblemente denunciados en Veracruz habían dado lugar a un cúmulo de aclaraciones y trámites necesarios para asegurar el reconocimiento de la propiedad legítima, aun cuando la ley favoreciera a las mujeres.

Hay también adjudicatarias que solicitaron copias de sus escrituras, lo que es indicio de que tuvieron alguna intención por recuperar los bienes, pero insuficiente para asentar que lo lograron, incluso que los hayan redimido. En ese caso se encontraron: María de Jesús Azcárate, Guadalupe Fernández de Villa, María de los Ángeles Falla de Sort, Antonia Marín Rodríguez de Castro, Francisca Párraga, Guadalupe Sanromán de Velasco, Pomposa Vázquez, Guadalupe Vega de Gutiérrez (aunque fue su heredera quien solicitó la escritura), Luisa Arce de Arreguín, Dolores Noriega y Ortiz, Carmen Vilela (quien sí recuperó la propiedad de uno de los tres bienes que originalmente le fueron adjudicados), Guadalupe y Margarita Meca y Josefa Zepeda de García. ${ }^{32}$

${ }^{31}$ FA, Adjudicación, Remigio Mateos (436), 26 de agosto de 1856, vol. 2933, ff. 162r.-166r., AGNCM.

32 Adjudicación, Francisco de Madariaga (426), 22 de septiembre de 1856, vol. 2880, ff. 515r.-522. Adjudicación, Manuel de Madariaga (431), 25 de septiembre de 1856, vol. 2911, ff. 220r.-223. Adjudicación, Remigio Mateos (436), 20 de septiembre de 1856, vol. 2933, ff. 314-317. Adjudicación, Juan Navarro (464), 27 de septiembre de 1856, vol. 3177, ff. 397r.-399. Adjudicación, Remigio Mateos (436), 19 de septiembre de 1856, vol. 2933, ff. 306309. Adjudicación, Mariano Vega (726), 18 de septiembre de 1856, vol. 5003, ff. 483-491r. Adjudicación, José María Natera (467), 20 de septiembre de 1856, vol. 3193, ff. 152-157. Adjudicación, José María Ramírez (612), 30 de septiembre de 1856, vol. 4133, ff. 324-329. Adjudicación, Juan Navarro (464), 22 de septiembre de 1856, vol. 3177, ff. 264r.-274. Adjudicación, Fermín Villa (719), 18 de septiembre de 1856, vol. 4837, ff. 105-110. Adjudicación, Agustín Pérez de Lara (Hda), 22 de septiembre de 1856, vol. 22, ff. 159-167. Adjudicación, Joaquín Vigueras (723), 22 de septiembre de 1856, vol. 4920 bis, ff. 91-94. Adjudicaciones, Agustín Pérez de Lara (Hda), 20, 23 y 30 de septiembre de 1856, vol. 22, ff. 134r.-145r., 172r.-183 y 282r-294. Todos en FA, AGNCM. 


\section{Conclusiones}

En su estudio sobre la desamortización, Jan Bazant afirmó que la ley del 25 de junio de 1856 era lógica, posible y se dio en un medio secularizador que sí pretendió realizar un cambio en la sociedad (Bazant, 1977, p. 315). Al reflexionar sobre la medida debe tenerse presente que confluyeron, primero, un diseño político y fiscal; segundo, un clima de opinión de ruptura, y tercero, la individuación del concepto de la propiedad y la importancia que se le concedió por los regímenes liberales. Reparar en estos aspectos hace posible, y necesario, problematizar sobre cuestiones más específicas del proceso.

La participación de las mujeres de la ciudad de México en la desamortización es una de esas especificidades. La única adjudicataria que expresó un discurso hasta cierto punto anticlerical, abrogada la Ley Lerdo en 1858, fue Guadalupe González de Cosío, quien no se encuentra entre las 29 mujeres que lograron ser propietarias con base en el proceso de desamortización. El 9 de marzo de 1858, Guadalupe se presentó ante el notario señalando que pese a lo dispuesto por la ley del 28 de enero y su reglamento "no presenta la comparente su consentimiento para que se cancele esta escritura [...] y pide que conste que reserva sus derechos para deducirlos cuando le convenga". ${ }^{33}$ El 1 de diciembre de 1865, la comisión segunda del Consejo de Estado del Imperio Mexicano declaró subsistente la adjudicación de Guadalupe, en uno de los bienes del convento de San Jerónimo, sin embargo, no consta que haya obtenido la propiedad.

Su discurso es muy sugerente para el análisis y advierte la necesaria confrontación de fuentes a la que deben someterse los protocolos notariales. Debe considerarse, por ejemplo, que Guadalupe tuvo los mismos apellidos que el mayordomo del convento de Santa Isabel: José Miguel González de Cosío (Staples, 1986, p. 161). Es posible presumir que lo anterior sea una coincidencia; sin embargo, tampoco debe perderse de vista que su nombre, junto con el de Manuela Bachiller y Loreto Vivanco de Morán -quienes sí obtuvieron la propiedad de los bienes adjudicados-, se encuentra entre las firmantes de una representación contra el proyecto del artículo $11^{\circ}$ constitucional, que pretendió establecer la libertad de cultos (Zamacois, 1880, t. XIv, pp. 1027-1039).

Ambos rasgos de su contexto hacen pensar que Guadalupe, lejos de pertenecer a un sector de la sociedad más liberal y secularizado que confiara en las bondades de la Ley Lerdo, articuló, en 1858, una estrategia que trató de preservar los derechos de la corporación en plena guerra civil. Esto, incluso con el partido conservador al frente del gobierno de la ciudad de México, lo que alude es a la extendida percepción sobre la inestabilidad.

Las dificultades que encontraron las mujeres que se han estudiado en estas páginas para hacerse con los bienes de las corporaciones, invitan a reflexionar sobre el cambio legal que hizo posible accedieran al ejercicio del derecho de propiedad. Este ejercicio se enlazó con dinámicas en las que el estado civil, la condición de clase y la etnia jugaron un papel tan decisivo como el que las convenciones sociales articularon en torno a la domesticidad, su conveniencia para el equilibrio social y los temores que la separación de la iglesia y el Estado entrañaron.

Las 29 mujeres que lograron la propiedad de los bienes adjudicados relajaron el estrecho margen al que la construcción de género del periodo las redujo. También participaron en las transformaciones que la medida produjo en una ciudad de México agitada por los cambios. Este hecho no es menor. El 9 de enero de 1858, el periódico La Sociedad advirtió: "falta la condición de legiti-

\footnotetext{
${ }^{33}$ FA, Adjudicación, José María Covarrubias (176), 22 de septiembre de 1856, vol. 1077, ff. 96-105, AGNCM.
} 
midad a los intereses creados por la ley Lerdo en perjuicio de los intereses legítimos de los antiguos y verdaderos propietarios". ${ }^{34}$ Estas palabras son contundentes porque retratan el conflicto institucional detrás de la inestabilidad política.

En principio, estas mujeres invalidaron los preceptos de derecho que cuestionaron la conveniencia de su ejercicio libre de la propiedad. Con base en la política ciega al género que atravesó a la Ley Lerdo, que en 1861 dio paso a un abierto apoyo para que las mujeres conservaran los bienes adjudicados, lograron construir estrategias para alcanzar la propiedad de los mismos. En este escenario, el formar parte del piso fiscal de la época, por medio del pago del derecho de traslación, muestra cómo el engranaje entre el fortalecimiento del erario público y la ampliación del número de propietarios, finalidad de la desamortización, no fue una idea descabellada, sino entorpecida por el conflicto político.

Las mujeres que lograron la propiedad de algún bien adjudicado mostraron una actitud que resistió la ola de disposiciones, a veces encontradas, sobre los bienes desamortizados y contravinieron los papeles que la tradición y la sociedad les asignó. Su presencia, si bien minoritaria respecto al número de adjudicaciones celebradas en el otoño de 1856, permite advertir, con base en los montos de los bienes apropiados, que el ejercicio del derecho de propiedad en la coyuntura de la Ley Lerdo no fue exclusivo de aquellas que formaron parte de la elite, sino que logró la participación de mujeres adscritas a distintos segmentos económicos de la sociedad.

\section{LISTA DE REFERENCIAS}

Arrom, S. M. (1988). Las mujeres de la ciudad de México, 1790-1857. México: Siglo Veintiuno Editores.

Bazant, J. (1972). Desamortización y nacionalización de los bienes de la Iglesia. En L. González (ed.), La economía mexicana en la época de Juárez (pp. 188-221). México: Secretaría de Industria y Comercio.

Bazant, J. (1977). Los bienes de la Iglesia en México, 1856-1875: Aspectos económicos y sociales de la revolución liberal. El Colegio de México. DoI: 10.2307/j.ctv233mr0

Bazant, J. (1979). La desamortización de los bienes de la Iglesia en Toluca durante la Reforma, 18561875. México: Biblioteca Enciclopédica del Estado de México.

Caballero, J. A. (2005). Derecho romano y codificación. Las sentencias de los jueces mexicanos en una época de transición, 1868-1872. En J. A. Caballero y O. Cruz (eds.), Historia del derecho: Memoria del Congreso Internacional de Culturas y Sistemas Jurídicos Comparados. México: Universidad Nacional Autónoma de México.

Carrasco, H. (2003). Derecho fiscal I. México: Iure.

Cervantes, F. J. (2004). La propiedad eclesiástica en Puebla en la primera mitad del siglo XIX. La formación de la opinión pública en favor de la desamortización. En M. del P. Martínez López-Cano, E. Speckman y G. von Wobeser (eds.), La Iglesia y sus bienes: De la amortización a la nacionalización (pp. 275-292). México: Universidad Nacional Autónoma de México.

Chowning, M. (2006). Rebellious nuns: The troubled history of a Mexican convent, 1752-1863. Oxford/Nueva York: Oxford University Press.

Curia filípica mejicana. Obra completa de práctica forense conteniendo además un tratado integro de la jurisprudencia mercantil (1991). México: Universidad Nacional Autónoma de México/Porrúa.

${ }^{34}$ La Sociedad. Periódico Político y Literario, ciudad de México. 
Deere, C. D. y León de Leal, M. (2002). Género, propiedad y empoderamiento: Tierra, Estado y mercado en América Latina. México: Universidad Nacional Autónoma de México.

Díaz, L. (1963). Versión francesa de México. Informes diplomáticos, 1853-1858. México: El Colegio de México.

Dublán, M. y Lozano, J. (eds.). (2004). La legislación mexicana de Manuel Dublán y José María Lozano. México: Suprema Corte de Justicia de la Nación/Tribunal Superior de Justicia del Estado de México/El Colegio de México/Escuela Libre de Derecho.

Escriche, J. (1993). Diccionario razonado de legislación civil, penal, comercial y forense. México: Universidad Nacional Autónoma de México/Instituto de Investigaciones Jurídicas/Porrúa.

Galván, M. (1851). Nuevo Febrero Mexicano. Obra completa de jurisprudencia teórico-práctica, dividida en cuatro tomos: En el primero y segundo se trata de la parte teórica; en el tercero de las sustanciaciones de todos los juicios y de todos los tribunales establecidos en la República; y en el cuarto del derecho administrativo. México: Impreso por Santiago Pérez.

González, M. R. (1998). El derecho civil en México 1821-1871 (Apuntes para su estudio). Ciudad de México, México: Universidad Nacional Autónoma de México.

González, R. (2011). Desamortización y propiedad de las elites en el noreste mexicano: 1850-1870. México: Fondo Ed. de Nuevo León/Universidad Autónoma de Nuevo León.

Gutiérrez, B. J. (1968). Leyes de Reforma: Colección de las disposiciones que se conocen con este nombre, publicadas desde el año de 1855 al de 1868. México: Imprenta de "El Constitucional".

Knowlton, R. J. (1985). Los bienes del clero y la reforma mexicana, 1856-1910. México: Fondo de Cultura Económica.

Lerdo de Tejada, M. (1857). Memoria presentada al excelentísimo señor presidente de la República por el C. Miguel Lerdo de Tejada, dando cuenta de la marcha que han seguido los negocios de la Hacienda Pública, en el tiempo que tuvo a su cargo la secretaría de ese ramo. México: Imprenta de Vicente García Torres.

Lira, A. (1983). Comunidades indígenas frente a la ciudad de México: Tenochtitlan, Tlatelolco, sus pueblos y barrios, 1812-1919. El Colegio de México. DoI: 10.2307/j.ctv3dnrqp

Lombardo de Ruiz, S. (ed.). (2009). Territorio y demarcación en los censos de población: Ciudad de México 1753, 1790, 1848 y 1882. México: Instituto Nacional de Antropología e Historia/Universidad Autónoma de la Ciudad de México/Apoyo al Desarrollo de Archivos y Bibliotecas de México, A. C./Centro de Investigación en Geografía y Geomática Ing. Jorge L. Tamayo.

Marino, D. (2001). La desamortización de las tierras de los pueblos (centro de México, siglo xix). Balance historiográfico y fuentes para su estudio. América Latina en la Historia Económica, 8(16), 33. DoI: 10.18232/alhe.v8i16.276

Mijangos, P. (2018a). Entre Dios y la república la separación Iglesia-Estado en México, siglo XIX. México: CIDE.

Mijangos, P. (2018b). La Reforma (1848-1861). México: Fondo de Cultura Económica.

Morales, M. D. (1995). La desamortización y su influencia en la estructura de la propiedad. Ciudad de México, 1848-1864. En M. P. Martínez (ed.), Iglesia, Estado y economía. Siglos хVI al XIX (pp. 179-204). México: Universidad Nacional Autónoma de México/Instituto de Investigaciones Dr. José María Luis Mora.

Pani, E. (2004). "La grande cuestión”: La desamortización de los bienes del clero, los conservadores y el imperio de Maximiliano. En M. del P. Martínez López-Cano, E. Speckman y G. von Wobeser (eds.), La iglesia y sus bienes: De la amortización a la nacionalización (pp. 307-318). México: Universidad Nacional Autónoma de México. 
Parra, A. (2018). No lo roba. Lo hereda. Francisca de Paula Pérez Galvez: Un perfil empresarial femenino entre negociantes decimonónicos. En R. M. Meyer y D. Salazar (eds.), Historias de comerciantes (pp. 45-62). México: Secretaría de Cultura/Instituto Nacional de Antropología e Historia.

Prieto, G. (1992). Memorias de mis tiempos. Obras completas I. México: Conaculta.

Ramos, C. (ed.) (2006). Presencia y transparencia: La mujer en la historia de México. México: El Colegio de México.

Rodríguez de San Miguel, J. N. (1991). Pandectas Hispano-Mexicanas. México: Universidad Nacional Autónoma de México.

Sánchez, C. (ed.). (2007). La desamortización civil en Oaxaca. México: UABJo/Universidad Nacional Autónoma de México.

Scott, J. W. y Lamas, M. (1996). El género: Una categoría útil para el análisis histórico. En El género: La construcción cultural de la diferencia sexual (pp. 265-302). México: Universidad Nacional Autónoma de México/Porrúa.

Staples, A. (1986). Mayordomos, monjas y fondos conventuales. Historia Mexicana, 36(1), 131 167.

Staples, A. (2004). Mujeres y dinero heredado, ganado o prestado. Las primeras décadas del siglo XIX mexicano. En P. Gonzalbo y B. Ares Queija (eds.), Las mujeres en la construcción de las sociedades iberoamericanas (pp. 271-294). Sevilla/México: Consejo Superior de Investigaciones Científicas/Colegio de México.

Staples, A. (2009). El miedo a la secularización o un país sin religión. México, 1821-1859. En P. Gonzalbo, A. Staples y V. Torres Septién (eds.), Una historia de los usos del miedo (pp. 273-290). México: Colegio de México/Universidad Iberoamericana.

Velázquez, A. (2018). Representaciones femeninas en la pintura del siglo XIX en México: Ángeles del hogar y musas callejeras. México: Universidad Nacional Autónoma de México.

Viveros, M. (2016). La interseccionalidad: Una aproximación situada a la dominación. Debate Feminista, 52, 1-17. DoI: 10.1016/j.df.2016.09.005

Zamacois, N. (1880). Historia de México, desde sus tiempos más remotos hasta nuestros días, escrita en vista de todo lo que de irrecusable han dado a luz los más caracterizados historiadores, y en virtud de documentos auténticos, no publicados todavía, tomados del Archivo Nacional de México, de las bibliotecas públicas, y de los preciosos manuscritos que, hasta hace poco, existían en las de los conventos de aquel país. Barcelona: J. F. Parres y cía. editores.

Zarco, F. (1957). Crónica del Congreso Extraordinario Constituyente [1856-1857]. México: El Colegio de México.

Archivos

AHNcm Archivo Histórico de Notarías de la Ciudad de México. 